\title{
MULTI-DETECTOR COMPUTED TOMOGRAPHY ROLE IN LOCAL STAGING OF COLONIC CARCINOMA
}

\author{
By \\ Kamal A. Oun, Amr M. Zayed and Ahmed M. El-Deeb \\ Department of Diagnostic and Interventional Radiology, Faculty of Medicine, Al-Azhar \\ University \\ Corresponding Author: Kamal Abd El-Aziz Oun, \\ E-mail: kamal_oun@gmail.com
}

\begin{abstract}
Background: Pre-operative staging is critical for the treatment and surgical planning of colonic carcinomas.

Objectives: To evaluate the role of the contrast enhanced multi-detector computed tomography (CEMDCT) in locoregional staging of the colonic carcinoma in correlation with pathological data as standard.

Patients and Methods: The study included 30 consecutive patients diagnosed with colonic carcinoma by biopsy and colonoscopy and referred from the clinic at the National Cancer Institute. MDCT was performed for all patients after being submitted to intravenous non ionic contrast and oral and rectal positive or negative colon opacification. All patients underwent surgery. Tumors were classified with the TNM staging system. The MDCT findings for each patient were recorded and correlated with operative and pathological findings as reference standard. The sensitivity, specificity, positive predictive value, negative predictive value and diagnostic accuracy were calculated.
\end{abstract}

Results: In the detection of extramural invasion, the sensitivity, specificity, positive predictive value (PPV), negative predictive value (NPV), and diagnostic accuracy of CEMDCT were 90\%, 70\%, 85.7\%, 77.8\% and $83.3 \%$ respectively. Regarding the accuracy of the $\mathrm{T}$ staging, the study accurately staged 20 patients $(66.6 \%)$.

In the detection of lymph node status, the sensitivity, specificity, positive predictive value, negative predictive value and diagnostic accuracy were $84.6 \%, 70.6 \%, 68.8 \%, 85.7 \%$ and $76.7 \%$ respectively.

Conclusions: Contrast enhanced multi-detector computed tomography (CEMDCT) is a sensitive tool in the evaluation of extra-mural invasion, and promising technique in the evaluation of preoperative staging and prognostic factors of colon cancer.

Keywords: Multidetector CT, Opacification, Colorectal Carcinoma and Locoregional.

\section{INTRODUCTION}

Colorectal cancer (CRC) is a major human health issue. Globally, it ranks third in incidence after lung and breast cancers. In developed areas such as North America, Australia, New Zealand and Western Europe, it appears even more frequently, being ranked the second (Tamas et al., 2015).
Imaging techniques play an important role in management of patients with colorectal carcinoma. Computed tomography (CT) became one of the important diagnostic tools in the evaluation of local characteristics, preoperative staging, and prognostic factors of colon cancers (Smith et al., 2010). 
Extramural invasion (EMI) is an important factor affecting the prognosis in patients with colon cancer. Preoperative CT can detect EMI in colon cancers with high sensitivity. In addition, CT-based T staging can be used to stratify patients into good and poor prognosis (Dighe et al., 2010).

Currently, tumors associated with good survival (T1and T2 tumors) are treated by curative surgical resection; T3, T4, and $\mathrm{N}+$ tumors may receive adjuvant chemotherapy with the objective of increasing survival rate. However, survival in patients with those tumors remains poor. To improve long term disease free survival, some studies are now assessing the interest of neo adjuvant chemotherapy in locally advanced colon cancer (Arredondo et al., 2013).

The aim of the present work was to evaluate the role of the MDCT in locoregional staging of the colonic carcinoma in correlation with pathological data as standard.

\section{PATIENTS AND METHODS}

This study was performed to evaluate the role of the MDCT in locoregional staging of the colonic carcinoma in correlation with pathological data as standard reference. The study was performed at national cancer institute (NCI), and approved by its ethical committee, and informed consents were given by all patients. The study was conducted on 30 consecutive patients referred from clinic at National Cancer Institute and diagnosed with colonic carcinoma, from October 2019 till February 2020.

\section{Inclusion Criteria:}

1. Patients with pathologically proven colonic cancer with different locations as follow:

- Cecal and ascending colon cancer.

- Transverse colon cancer.

- Descending colon cancer.

- Sigmoid colon cancer.

2. Patients underwent surgical resection after diagnosis.

\section{Exclusion Criteria:}

- Patients with renal impairment.

- Patients underwent pre-operative chemotherapy.

- Inoperable patients due to lack of operative data.

- Patients with rectal carcinomas due to better MRI and rectal ultrasound staging and high probability of preoperative chemotherapy.

Reference standard: The reference standard in this study was the pathological data regarding the mural invasion and nodal metastasis acquired after surgical operations for the patients.

\section{Image acquisition:}

- CT examination protocol design: CECT exams were performed on a GE light speed VCT 64 multislice CT scanner.

Patient's preparation was by oral administration of $800-1200 \mathrm{ml}$ water (negative or positive contrast medium) two hours before scanning, and enhanced CT study performed 70 second after the starting of intravenous non-ionic contrast injection (ultravist 370; Bayer Schering 
Pharma, Berlin, Germany) with peripheral venous access at rate of $2.5-3.5 \mathrm{ml} / \mathrm{s}$ using an automated power injector system.

All patients were scanned craniocaudally while in the supine position. Spiral scanning was performed in the conventional spiral mode at a tube voltage of $120 \mathrm{kVp}$ (200 milli-ampere seconds, 0.8 pitch, 0.5 s/rotation, DFOV $42 \mathrm{em} 2$, matrix $512 \mathrm{x}$ 512, and 1.2-mm collimation). Scans were acquired during the portal-venous phase.

\section{Image analysis:}

For analysis, images were transferred to a workstation using the Digital Imaging and Communications in Medicine (DICOM). The findings for each patient were recorded; the presence, location and morphological characterization of colonic carcinoma were assessed. Tumor localization were categorized under eight regions, caecum, ascending colon, hepatic flexure, transverse colon, splenic flexure, descending colon and sigmoid colon. $\mathrm{T}$ and $\mathrm{N}$ staging was based on the international TNM classification, as follows.

\section{T staging:}

T1 stage (tumor invading submucosal layer) was described as intraluminal extension without intestinal wall thickening, T2 stage (tumor invading the muscularis propria but not through) was evaluated as asymmetrical wall thickening with clear adjacent pericolonic fat tissue and T3 stage (tumor penetrating through the muscularis propria to the subserosa or into non peritonealized pericolonic tissue) was described as smooth or nodular extension of a discrete mass through the intestinal wall into pericolonic tissues.
With the last TNM revision, T4 lesions were reevaluated as $\mathrm{T} 4 \mathrm{a}$ (tumor penetrates to visceral peritoneal surface) and $\mathrm{T} 4 \mathrm{~b}$ (tumor invades other organs or structures). In this study $\mathrm{T} 1$ and $\mathrm{T} 2$ were considered as the same due to difficulty in distinguishing them on the MDCT.

\section{N staging:}

For nodal evaluation, N0 was evaluated as no lymph nodes, N1 was evaluated as one to three lymph nodes, with short axis more than $5 \mathrm{~mm}$, lymph node with rounded configuration or three abnormally clustered lymph nodes, N2 was evaluated as four or more lymph nodes more than $5 \mathrm{~mm}$ in short axis, or rounded in configuration or four or more abnormally clustered lymph nodes. In this study any lymph node with central necrosis or irregular margins was considered as positive.

\section{Statistical analysis:}

Recorded data were analyzed using the statistical package for the social sciences, version 20.0 (SPSS Inc., Chicago, Illinois, USA). Quantitative data were expressed as mean \pm standard deviation (SD). Qualitative data were expressed as frequency and percentage.

\section{The following tests were done:}

- Chi-square (x2) test of significance was used in order to compare proportions between qualitative parameters.

- Kappa measure of agreement between Radiological MDCT and Histopathological in detecting local staging of colonic cancer.

- Evaluation of Diagnostic Performance:

- Sensitivity. 
- Specificity.

- PPV.

- NPV.

- FN.

- FP.
- Accuracy.

- The confidence interval was set to $95 \%$ and the margin of error accepted was set to $5 \%$.

- P-value $<0.05$ was considered significant.

\section{RESULTS}

MDCT was performed in 30 (18 male and 12 female) cases of proved colon carcinoma. The mean age of the patients was 59.4 YRS, most of the colonic carcinomas were located in sigmoid colon (No.14, 46.7\%), descending colon (No.6, $20 \%$ ), hepatic flexure (No.4 13.3\%), each of the ascending, caecum and transverse colon was (No.2, 6.7\% for each of them).

Histopathology was performed for all patients, the majority of the patients were staged as T3 (No16, 53.3\%), 10 patients $(33.3 \%)$ were stage as $\mathrm{T} 2$ and 4 patients $(13.3 \%)$ were staged as $\mathrm{T} 4$.

Radiological T staging was categorized as under staging, accurate staging and over staging in correlation with histopathological data. On MDCT 7 out of 10 patients were accurately staged as $\mathrm{T} 2$ and 3 were over staged as T3 on MDCT. MDCT correctly staged 10 out of 16 patients as T3 on histopathology, four patients were over staged and two patients were under staged. MDCT correctly staged 3 patients out of 4 as T4 and one patient was under staged as T3. The number of under staged, accurately staged and over staged patients was 3 patients (10\%), 20patients (66.6\%) and 7 patients (23.3\%) respectively (Table 1).

Table (1): Relation between Histopathological data and radiological MDCT in T staging of the study group $(n=30)$

\begin{tabular}{|c|c|c|c|c|c|c|c|c|}
\hline \multirow{2}{*}{ Histopathological } & & & & & & & \multirow[b]{2}{*}{ Total } & \multirow{2}{*}{$\begin{array}{c}\text { Kappa } \\
\text { test }\end{array}$} \\
\hline & \multicolumn{2}{|c|}{$\mathbf{T 2}$} & \multicolumn{2}{|c|}{ T3 } & \multicolumn{2}{|c|}{$\mathbf{T 4}$} & & \\
\hline $\begin{array}{l}\text { Radiologica } \\
\text { MDCT }\end{array}$ & No. & $\%$ & No. & $\%$ & No. & $\%$ & No. & p-value \\
\hline $\mathrm{T} 2$ & 7 & $23.3 \%$ & 2 & $6.7 \%$ & 0 & $0.0 \%$ & 9 & \\
\hline T3 & 3 & $10.0 \%$ & 10 & $33.3 \%$ & 1 & $3.3 \%$ & 14 & \\
\hline $\mathrm{T} 4$ & 0 & $0.0 \%$ & 4 & $13.3 \%$ & 3 & $10.0 \%$ & 7 & $<0.001$ \\
\hline Total & 10 & $33.3 \%$ & 16 & $53.3 \%$ & 4 & $13.3 \%$ & 30 & \\
\hline
\end{tabular}

Statistical analysis of these results showed significant agreement between the two modalities in the detection. Comparison of Histopathological and radiological MDCT regarding $\mathrm{T}$ staging yielded weighted Kappa value of 0.548 . Evidence of extra mural invasion of the tumor (T3/T4) was determined and compared with histopathological and surgical results (Table 2). 
Table (2): CEMDCT evaluation of EMI in correlation with histopathological findings

\begin{tabular}{|c|c|c|c|c|}
\hline \multirow{3}{*}{$\begin{array}{l}\text { Histopathological data: } \\
\text { Extra Mural Invasion }\end{array}$} & \multirow{2}{*}{\multicolumn{2}{|c|}{ T3/4 }} & \multirow{2}{*}{\multicolumn{2}{|c|}{ T2 }} \\
\hline & & & & \\
\hline & No. & $\%$ & No. & $\%$ \\
\hline $\mathrm{T} 3 / 4$ & $\mathrm{TP}=18$ & $60 \%$ & $\mathrm{FP}=3$ & $10 \%$ \\
\hline $\mathrm{T} 2$ & $\mathrm{FN}=2$ & $6.6 \%$ & $\mathrm{TN}=7$ & $23.3 \%$ \\
\hline Total & 20 & $66.6 \%$ & 10 & $33.3 \%$ \\
\hline Sensitivity & \multicolumn{4}{|c|}{$90 \%$} \\
\hline Specificity & \multicolumn{4}{|c|}{$70 \%$} \\
\hline Positive predictive value & \multicolumn{4}{|c|}{$85.7 \%$} \\
\hline Negative predictive value & \multicolumn{4}{|c|}{$77.8 \%$} \\
\hline Accuracy & \multicolumn{4}{|c|}{$83.3 \%$} \\
\hline $\mathrm{p}$-value & \multicolumn{4}{|c|}{$<0.001 \mathrm{HS}$} \\
\hline
\end{tabular}

Diagnostic performance for prediction of extra mural invasion using the MDCT, with sensitivity of $90 \%$ specificity of $70 \%$ positive predictive value of $85.7 \%$, negative predictive value of $77.8 \%$ with diagnostic accuracy of $83.3 \%$, with $\mathrm{p}$ value $<0.001$ (Figure 1).

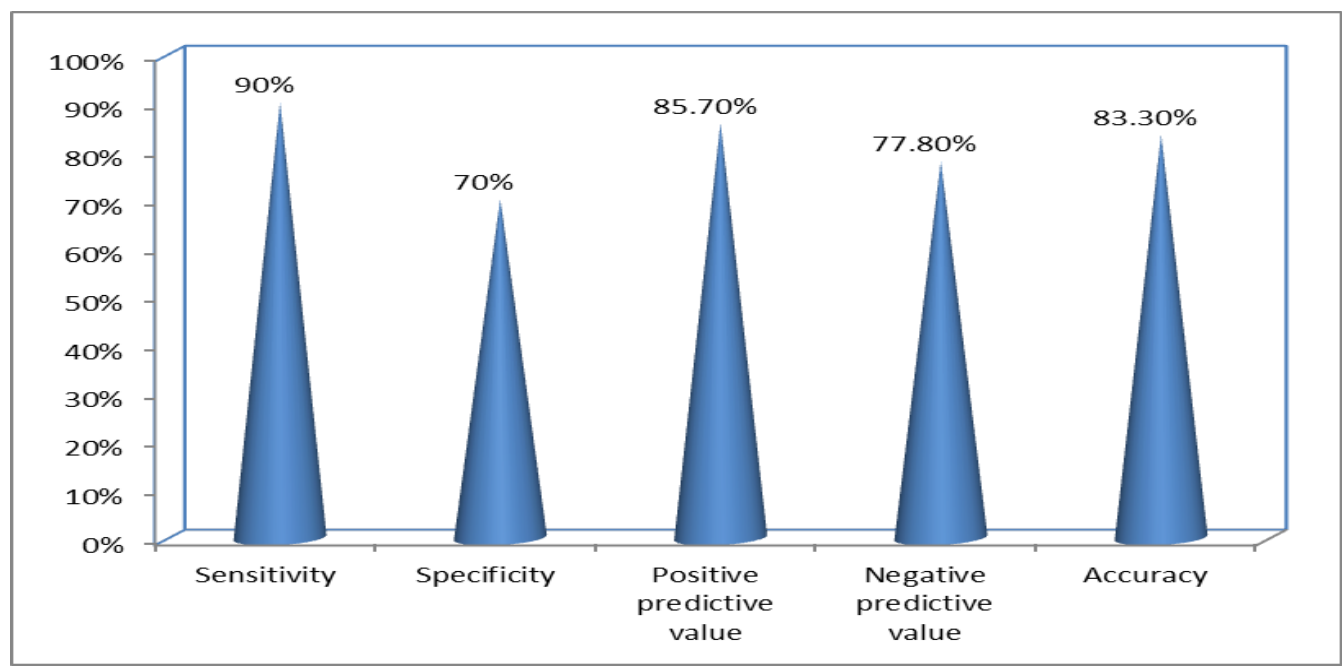

Figure (1): Diagnostic performance for prediction of extra mural invasion by the MDCT

According to histopathology of lymph node status the majority of the patients (No.17, 56.7\%) were staged as N0, 10 patients were staged as N1 and 3 patients were staged as N2. MDCT correctly staged 12 out of 17 N0 patients (true negative), the remaining 5 patients were over staged as $\mathrm{N} 1$ (false positive). Regarding N1 patients, MDCT correctly staged 7 out of 10 patients, 2 patients were under staged and one patient was over staged. Regarding to N2 patients, MDCT correctly staged 2 patients out of 3 and under staged one patient as N1. MDCT correctly staged $21(70 \%)$ patients out of 30 , under staged $3(10 \%)$ patients and over staged $6(20 \%)$ patients (Table 3). 
Table (3): Relation between Histopathological data and radiological MDCT in lymph nodes of the study group $(n=30)$

\begin{tabular}{|c|c|c|c|c|c|c|c|c|}
\hline \multirow{2}{*}{$\begin{array}{r}\text { Histopathological } \\
\text { data } \\
\text { Lymph node }\end{array}$} & & & & & & & \multirow{2}{*}{ Total } & \multirow{2}{*}{$\begin{array}{c}\text { Kappa } \\
\text { test }\end{array}$} \\
\hline & \multicolumn{2}{|c|}{ No } & \multicolumn{2}{|c|}{ N1 } & \multicolumn{2}{|c|}{ N2 } & & \\
\hline $\begin{array}{l}\text { Radiological } \\
\text { MDCT } \\
\text { Lymph node }\end{array}$ & No. & $\%$ & No. & $\%$ & No. & $\%$ & No. & p-value \\
\hline No & 12 & $40.5 \%$ & 2 & $6.6 \%$ & 0 & $0.0 \%$ & 14 & \\
\hline N1 & 5 & $16.6 \%$ & 7 & $23.3 \%$ & 1 & $3.3 \%$ & 13 & $<0001$ \\
\hline $\mathrm{N} 2$ & 0 & $0.0 \%$ & 1 & $3.3 \%$ & 2 & $6.6 \%$ & 3 & .001 \\
\hline Total & 17 & $56.7 \%$ & 10 & $33.3 \%$ & 3 & $10.0 \%$ & 30 & \\
\hline
\end{tabular}

Statistical analysis of these results showed significant agreement between the two modalities in the detection. Comparison of Histopathological and radiological MDCT regarding lymph node yielded weighted Kappa value of 0.484 (Table 4).

Table (4): CEMDCT evaluation of lymph nodes status in correlation with histopathological data

\begin{tabular}{|c|c|c|c|c|}
\hline \multirow{3}{*}{$\begin{array}{l}\text { Radiological MDCT } \\
\text { Lymph node }\end{array}$} & \multirow{2}{*}{\multicolumn{2}{|c|}{$\mathrm{N} 1 / 2$}} & \multirow{2}{*}{\multicolumn{2}{|c|}{ No }} \\
\hline & & & & \\
\hline & No. & $\%$ & No. & $\%$ \\
\hline $\mathrm{N} 1 / 2$ & $\mathrm{TP}=11$ & $84.6 \%$ & $\mathrm{FP}=5$ & $29.4 \%$ \\
\hline N0 & $\mathrm{FN}=2$ & $15.4 \%$ & $\mathrm{TN}=12$ & $70.6 \%$ \\
\hline Total & 13 & $100.0 \%$ & 17 & $100.0 \%$ \\
\hline Sensitivity & \multicolumn{4}{|c|}{$84.60 \%$} \\
\hline Specificity & \multicolumn{4}{|c|}{$70.60 \%$} \\
\hline Positive predictive value & \multicolumn{4}{|c|}{$68.80 \%$} \\
\hline Negative predictive value & \multicolumn{4}{|c|}{$85.70 \%$} \\
\hline Accuracy & \multicolumn{4}{|c|}{$76.70 \%$} \\
\hline $\mathrm{p}$-value & \multicolumn{4}{|c|}{$<0.001 \mathrm{HS}$} \\
\hline
\end{tabular}

Diagnostic performance for prediction of lymph node status using the radiological MDCT, with sensitivity of $84.6 \%$ specificity of $70.6 \%$ positive predictive value of $68.8 \%$, negative predictive value of $85.7 \%$ with diagnostic accuracy of $76.7 \%$, with p-value $<0.001$ (Figure 2). 


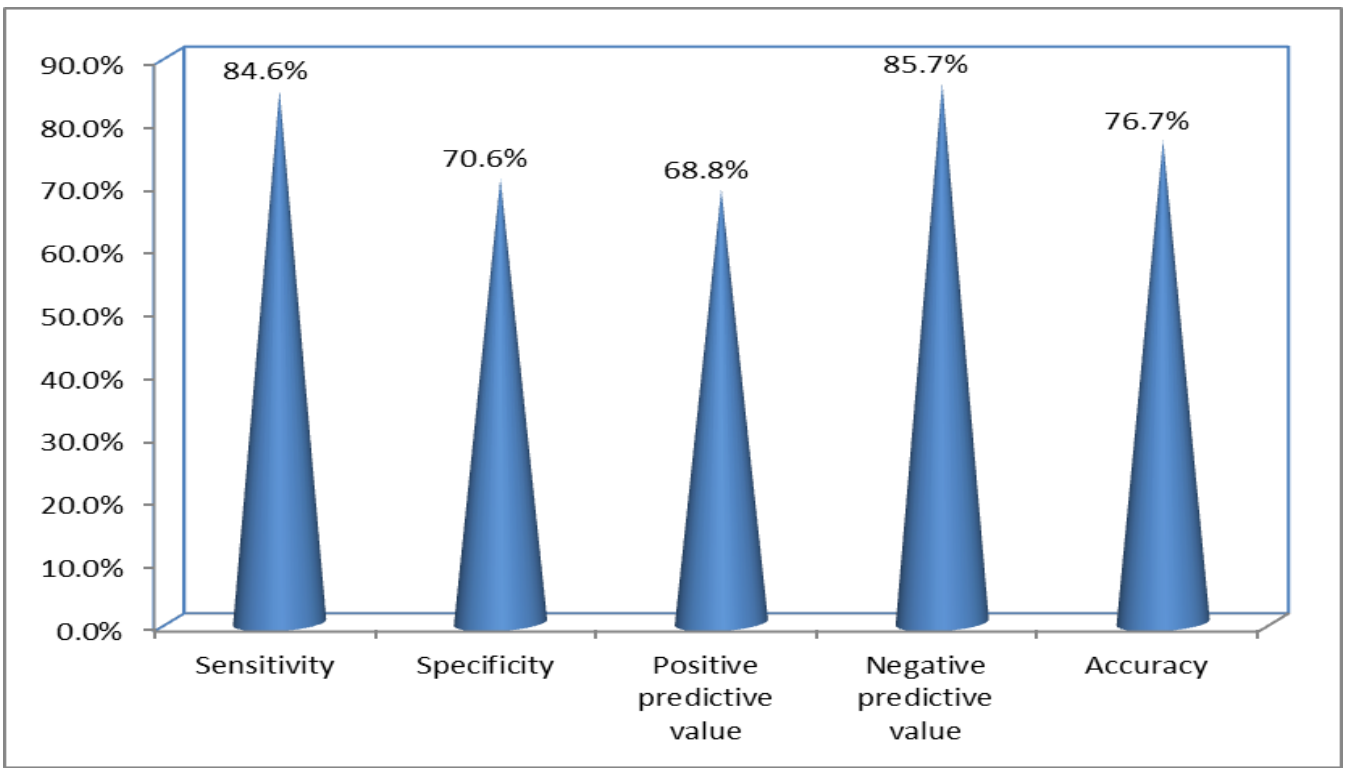

Figure (2): Diagnostic performance for prediction of lymph node status using the MDCT

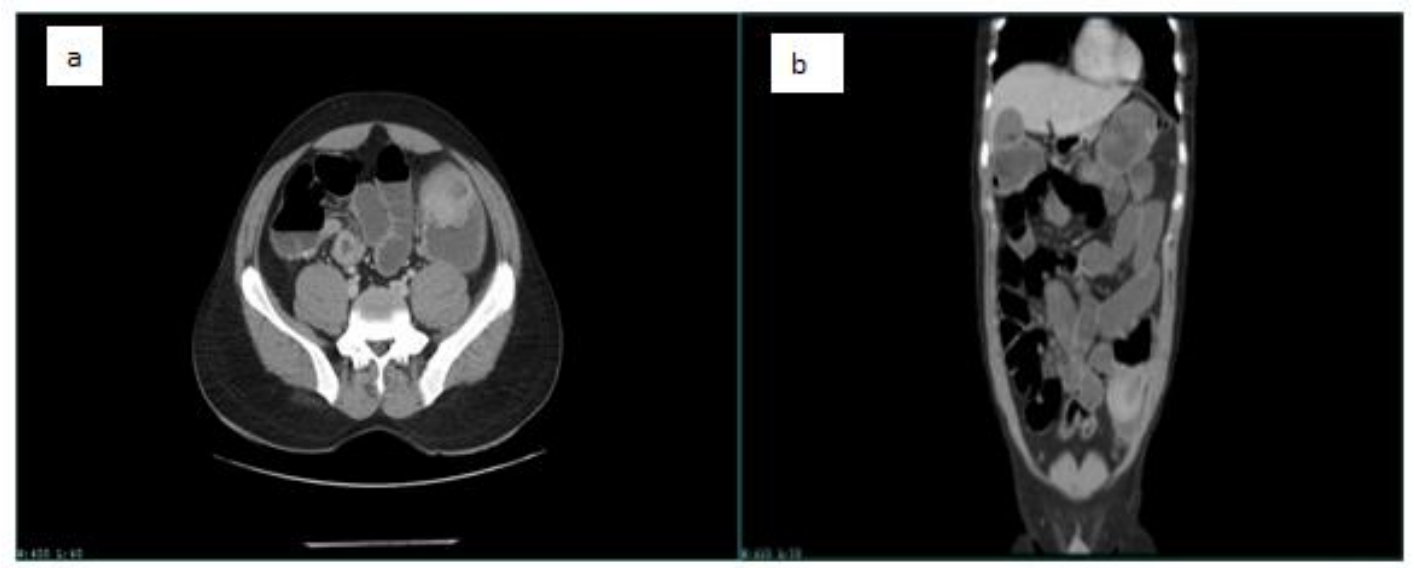

Figure (3): Case No.1 CEMDCT of 69 years male patient showing accurately staged, pathologically proven descending colon adenocarcinoma pT2N0 (a) axial and (b) sagittal shows enhancing soft tissue mass and smooth asymmetrical bowel wall thickening with no pericolonic extension. 


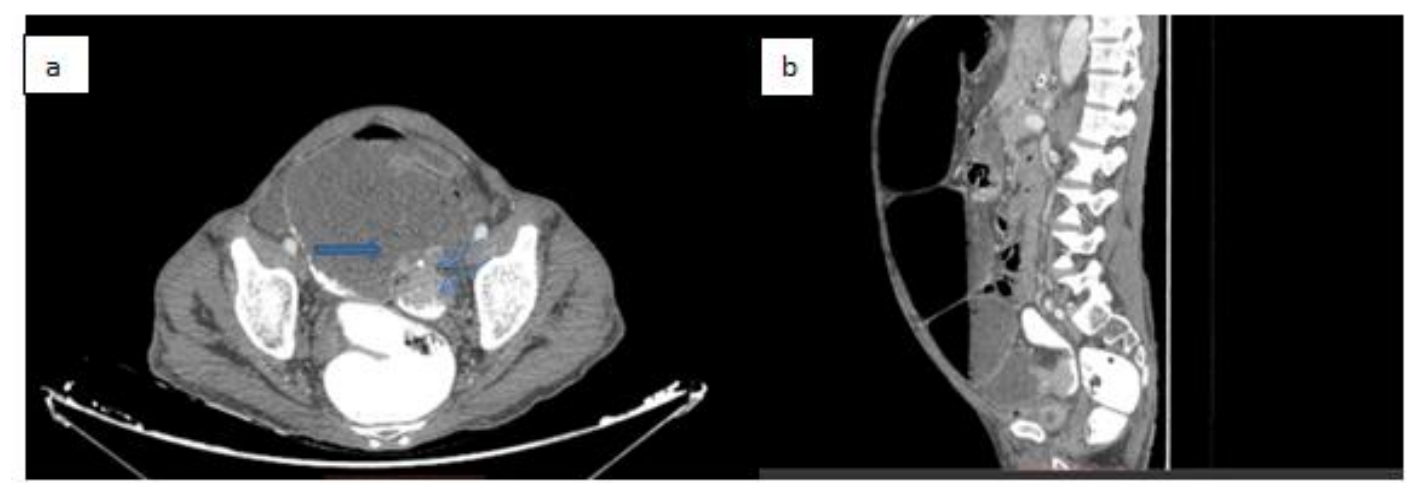

Figure (4): Case No.2 CEMDCT of 67 years old male patient, (a) axial and (b) sagittal shows accurately staged sigmoid colon adenocarcinoma pT3NO with proximal and distal shouldering (arrow) and pericolonic soft tissue extension (double arrow) with associated multiple air fluid levels denoting intestinal obstruction.

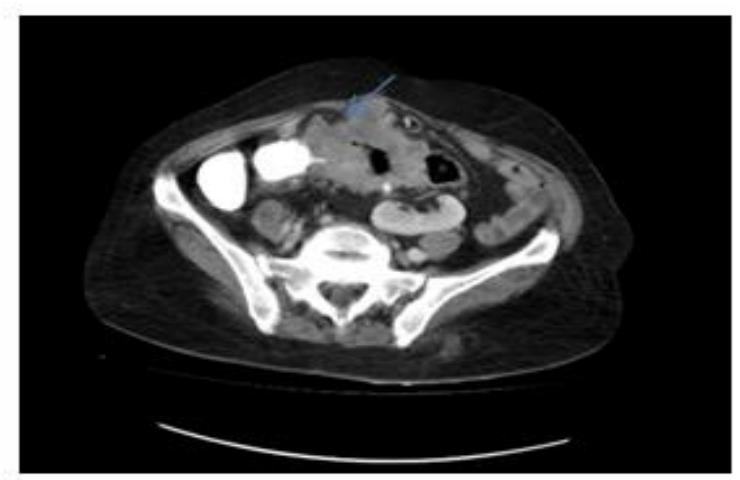

Figure (5): Case No.3 CEMDCT of 72 years old female patient, axial image of pathologically proven sigmoid adenocarcinoma pT4N1 shows irregular mural thickening seen involving the sigmoid colon, mounting to mass formation and inseparable from the anterior abdominal wall with associated marked luminal narrowing and pathologically enlarged perifocal lymph node (arrow). Note left pelvic kidney.

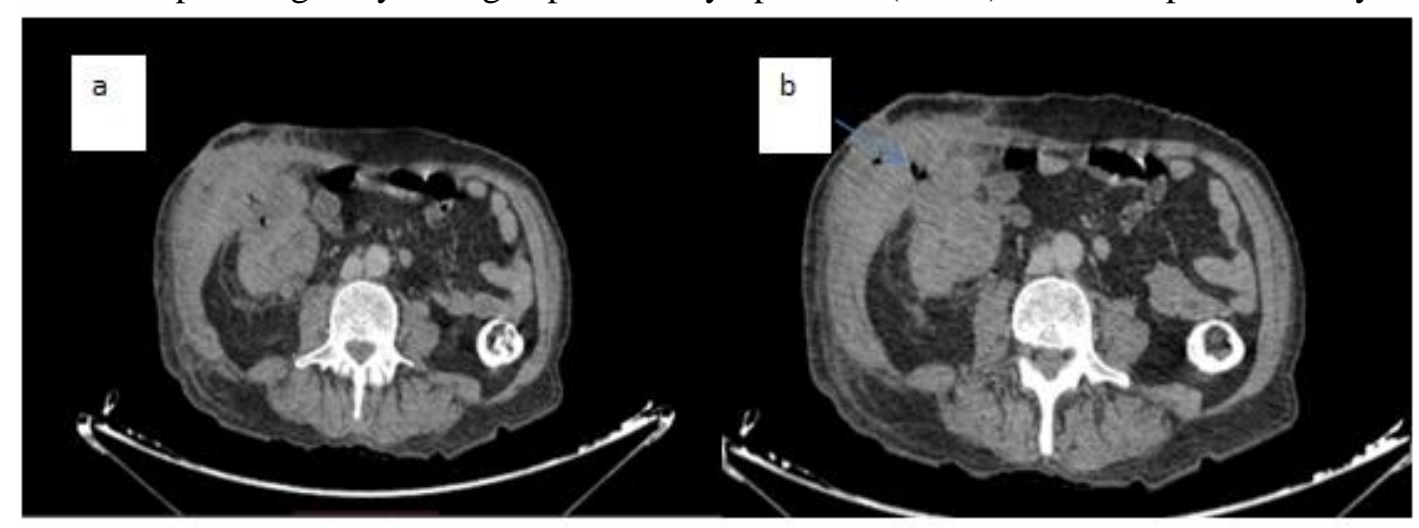

Figure (6): Case No.4 Overstaged 61 year old patient with ascending colon adenocarcinoma pT3N0. CEMDCT axial images (a\&b) show irregular circumferential heterogeneously enhancing soft tissue mural thickening with associated perifocal stranding inseparable from the anterior abdominal wall with lymph node enlargement(assessed as T4N1 lesion). Note inflammatory and edematous changes seen at the right abdominal muscles and the air loculi seen within due to colonic wall perforation (arrow), the removed lymph nodes showed reactive inflammatory changes and were negative for metastatic spread. 


\section{DISCUSSION}

Colorectal cancer (CRC) is a major human health issue. Globally, it ranks third in incidence. In developed areas, it appears even more frequently, being ranked the second (Tamas et al., 2015). Computed tomography (CT) became one of the important diagnostic tools in the evaluation of local characteristics, preoperative staging, and prognostic factors of colon cancers (Smith et al., 2010). Extramural invasion (EMI) is an important factor affecting the prognosis in patients with colon cancer. Preoperative CT can detect EMI in colon cancers with high sensitivity (Dighe et al., 2010).

Elibol et al. (2015) concluded that MDCT is a promising technique with moderate interobserver agreement in detection of extra mural invasion and lymph node metastases. In determining extra mural invasion (tumors that confined to bowel wall $\mathrm{T} 1 / 2$ and those invade beyond muscularis propria $\mathrm{T} 3 / 4$ ), the sensitivity, specificity and the diagnostic accuracy were $(81 \%, 50 \%$ and $81 \%$ respectively) for observer 1 and (87\%, $75 \%$ and $84 \%$ respectively) for observer 2 Nerad et al. (2016) reported in their metaanalysis sensitivity and specificity (90\% and $69 \%$ respectively) regarding EMI. They stated that the use of a thin imaging slice $(<5 \mathrm{~mm})$ improved the sensitivity and specificity to, for the detection of tumor growth beyond the bowel wall; hence the sensitivity was higher in studies with a slice thickness of less than $5 \mathrm{~mm}$ than in studies using a slice thickness of 5 $\mathrm{mm}$ or more. This improved sensitivity can be explained by the improved detection of minimal pericolonic fat infiltration due to tumor ingrowth.
Specificity, however, remained similar, confirming the inability of CT to differentiate between desmoplastic and neoplastic pericolonic fat infiltration that and due to the fact that radiologists, to minimize the risk for under staging, interpret minimal pericolonic fat stranding due to benign desmoplastic reaction as tumor invasion.

The result in this study was almost comparable with Nerad et al. (2016) with sensitivity, specificity, PPV, NPV and diagnostic accuracy $(90 \%, 70 \%, 85.7 \%$, $77.8 \%$ and $83.3 \%$ respectively).The high sensitivity regarding EMI in this is study due to the use of slice thickness less than $5 \mathrm{~mm}$ that allow better detection of tumor growth beyond the wall with reduced specificity in comparison to sensitivity due to interpretation of desmoplastic reaction as tumor invasion.

In their meta-analysis Dighe et al. (2010) showed that sensitivity and specificity of differentiating between $\mathrm{T} 1 / \mathrm{T} 2$ versus $\mathrm{T} 3 / \mathrm{T} 4$ is 86 and $78 \%$, respectively. They stated that, the most impressive results have been demonstrated by the studies that have utilized sections thicknesses of $5 \mathrm{~mm}$ or less. In the study of Sibileau et al. (2014) they used only water enema (WE-MDCT), the accuracy in differentiating T3/T4staging from $\mathrm{T} 1 / \mathrm{T} 2$ staging was $90.6 \%$, 97.7\% sensitivity, $\quad 60 \%$ specificity, 85.7\% NPV, and 91.3\%PPV. They stated that WE-MDCT allow better distention of the colon. Their initial assumption was that the distension of the colon lumen with water would allow the smoothness of the colon wall to be assessed; hence the higher sensitivity is due to the use of water enema and iodine contrast injection 
enhances the visualization and hence the analysis of the tumor.

Regarding the $\mathrm{T}$ staging, our study accurately staged $20(66.6 \%)$ patient out of 30 , with seven $(23.3 \%)$ patients over staged due to pericolonic stranding and desmoplastic reaction without actual tumoral extension and three (10\%) patients under staged due to the presence of micro invasion. In comparison to $55 \%$ for observer 1 and $51 \%$ for observer 2 in. In the study of Smith et al. (2010) the accuracy of $\mathrm{T}$ staging was $60.3 \%$ and $60.8 \%$ for observers $\mathrm{A}$ and B. For the correct recognition of extramural tumor invasion (stage pT3 or pT4), observer A was $83.3 \%$ accurate compared with histology (92.4\% sensitivity; $42.1 \%$ specificity; positive predictive value (PPV) 89.8\%). Observer B achieved $76.2 \%$ accuracy with sensitivity, specificity and PPV of $85.9 \%, 61.1 \%$ and $92.4 \%$, respectively.

Regarding the nodal involvement, Sibileau et al. (2014), in their study for each criterion in the nodal involvement (density more than 100 after iv contrast, size equal or more than $5 \mathrm{~mm}$ and number equal or more than 3 ), the highest sensitivity was for the size $95.5 \%$ and the highest specificity was for the density $67.7 \%$, with over all sensitivity of $77.3 \%$ and specificity of $77.4 \%$. In our study the results were almost comparable with Sibileau et al. with sensitivity, specificity, PPV, NPA and DA (84.6\%, 70.6\%, $68.8 \%, 85.7 \%$, and $76.7 \%$ ). The sensitivity in our study was higher $(84.6 \%$ compared to $77.3 \%$ ), and the specificity was slightly lower $(70.6 \%$ compared to $77.4 \%)$. This slight better specificity is due to the association of the three criteria (size, number and density).

In Dighe et al. (2010) meta-analysis, they reported sensitivity of $70 \%$ and specificity of $78 \%$. Their meta-analysis showed that the better specificity was in the studies that considered the lymph nodes to be metastatic with short axis to be $1 \mathrm{~cm}$ or more.

In the study of Elibol et al. (2015), they reported sensitivity and specificity of ( $84 \%$ and $46 \%$ respectively) for observer 1 and $(84 \%$ and $56 \%)$ for observer 2 with DA of $70 \%$. They stated that one of the main limitations of $\mathrm{CT}$ in preoperative staging of colon cancer is the low accuracy rate in $\mathrm{N}$ staging and that the sensitivity was higher but specificity was lower compared with the meta-analysis of Dighe et al. as the threshold value for pathologic lymph node is $1.0-1.5 \mathrm{~cm}$ in this study compared to the value that was determined in their study to be $0.5 \mathrm{~cm}$.

In the study of Narayanan et al. (2014), they used single slice computed tomography with only $5 \mathrm{~mm}$ slice thickness and lymph nodes were considered positive if larger than $1 \mathrm{~cm}$ in diameter or 3 or more clustered lymph nodes, they reported sensitivity and specificity of (60\% and $79 \%$ respectively), hence the use of multi-detector CT with thin slices and multiple reformatted images enhances enable better delineation of the size and borders of the lymph nodes and increases the sensitivity in the expense of the specificity.

False positive results from enlarged lymph nodes because of inflammatory changes and false negative results are caused by microscopic metastases in 
lymph nodes with normal size and contour.

Limitation of the study include: Patients with neoadjuvent chemotherapy were not included in the study. Inoperable patients were left out of evaluation due to inability to acquire post-operative data.

\section{CONCLUSION}

MDCT is a sensitive tool in the evaluation of extra mural invasion and promising technique in the evaluation of preoperative staging and prognostic factors of colon cancer. It could be helpful in differentiating $\mathrm{T} 1 / \mathrm{T} 2$ and T3/T4 subgroups with accuracy and reproducibility. However, Identification of malignant lymph nodes remains a challenge.

\section{REFERENCES}

1. Arredondo J, Pastor $\mathrm{C}$ and Baixauli $\mathrm{J}$. (2013): Preliminary outcome of a treatment strategy based on perioperative chemotherapy and surgery in patients with locally advanced colon cancer. Colorectal Dis., 15:552-557.

2. Dighe $S$, Purkayastha $S$, Swift I, Tekkis PP, Darzi A, A'Hern R and Brown G. (2010): Diagnostic precision of CT in local staging of colon cancers: a meta-analysis. Clinical Radiology, 65(9): 708-719.

3. Elibol FD, Obuz F, Sokmen S, Terzi C, Canda AE, Sagol $O$ and Sarioglu S. (2015): The role of multidetector $\mathrm{CT}$ in local staging and evaluation of retroperitoneal surgical margin involvement in colon cancer.
Diagnostic and Interventional Radiology, 22(1): 5-12.

4. Narayanan S, Clara N, Bhata A, Wing J, Rana S, Bhasin D and Khandelwal $N$. (2014): Staging of colorectal cancer using contrast enhanced Multidetector computed tomographic colonography. Singapore Med J., 55(12): 660-666.

5. Nerad E, Lahaye MJ, Maas M, Nelemans $P$, Bakers FCH, Beets GL and Beets-Tan RGH. (2016): Diagnostic Accuracy of CT for Local Staging of Colon Cancer: A Systematic Review and Meta-Analysis. American Journal of Roentgenology, 207(5): 984-995.

6. Sibileau E, Ridereau-Zins C, Vanel D, Pavageau AH, Bertrais S, Metivier-Cesbron E and Aubé C. (2014): Accuracy of waterenema multidetector computed tomography (WE-MDCT) in colon cancer staging: a prospective study. Abdominal Imaging, 39(5): 941-948.

7. Smith NJ, Bees N, Barbachano Y, Norman AR, Swift RI, Brown G. (2010): Preoperative computed tomography staging of nonmetastatic colon cancer predicts outcome: implications for clinical trials. Brit J Cancer, 96:1030-1036.

8. Tamas K, Walenkamp AM and de Vries EG. (2015): Rectal and colon cancer: Not just a different anatomic site. Cancer Treat Rev., 41(8):671-679. 


\section{دور الاشعة المقطعية متعددة الكواشف في التقييم الموضعي لسرطان القولوز}

كمال عبد العزيز عون, عمرومحمود زايد, أحمد محمد الديب

قسم الاشعة التشخيصية والتداخلية, كلية الطب، جامعة الازهر

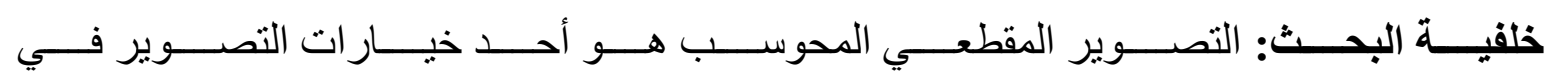

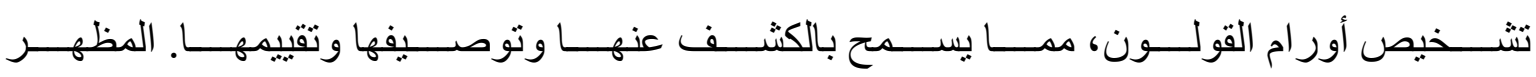

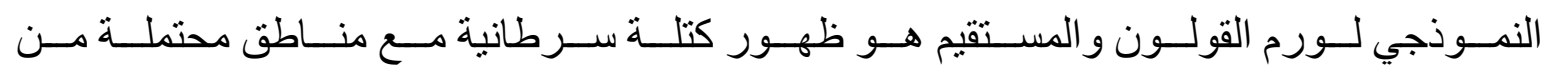

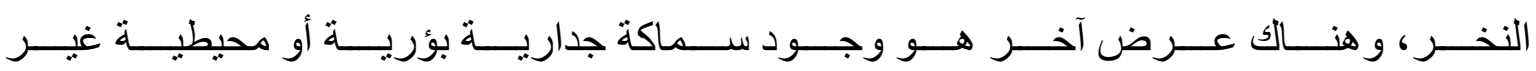
منتظمة، مع وجود ضيق بتجويف القولون.

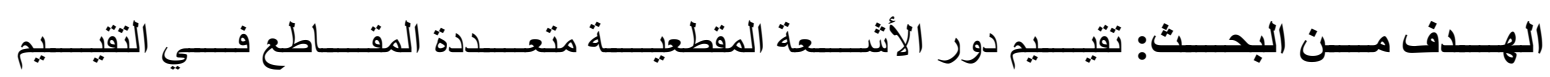

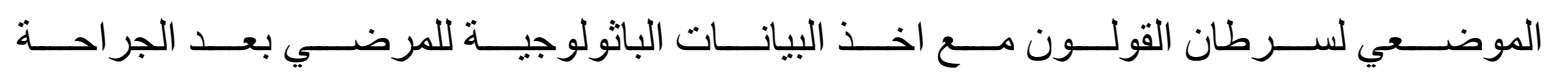
كمعيار.

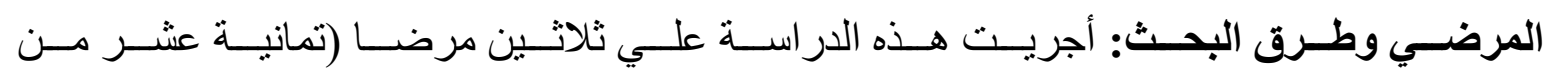

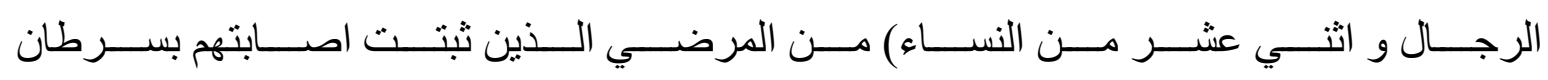

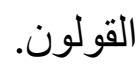

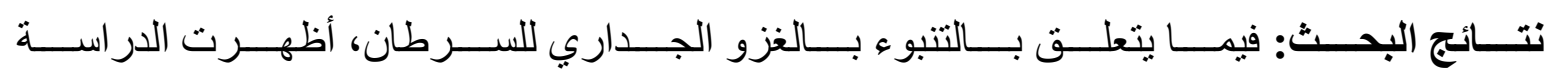

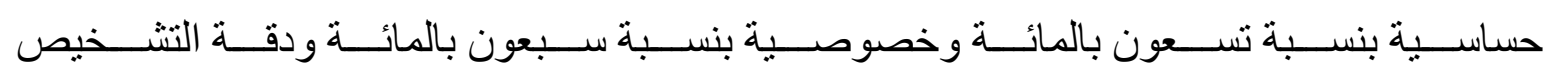

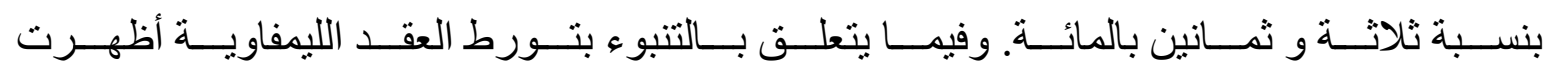

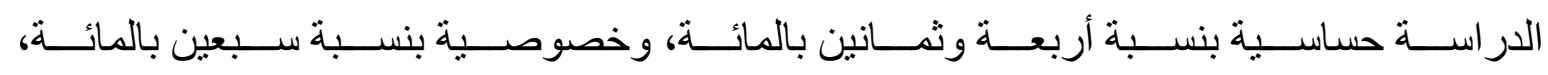
ودقة تشخيصية بنسبة سبعة و ستين بالمائة.

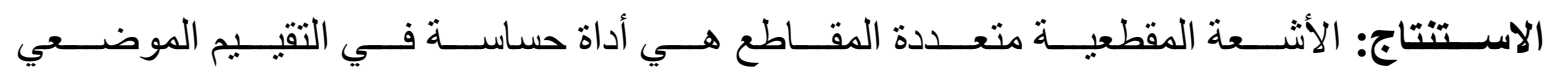

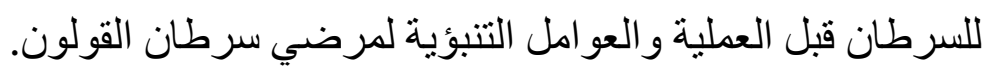

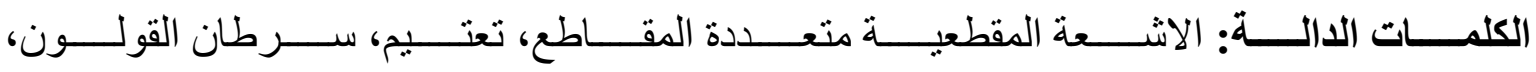

